\title{
Work-related musculoskeletal disorders and associated factors among cleaners of health institutions in Gondar town, Northwest Ethiopia: an institution based cross-sectional study
}

Jemal Suleyman ${ }^{1}$, Asmare Yitayeh Gelaw ${ }^{1 *}$

\section{Author Affiliations}

1, Department of physiotherapy, School of Medicine, College of Medicine and Health Sciences, University of Gondar, Gondar, Ethiopia

E-mail: jemsul950@gmail.com

Mob.: +251-986665381

\section{Corresponding author}

*Asmare Yitayeh: Lecturer, Department of physiotherapy, School of Medicine, College of Medicine and Health Sciences, University of Gondar, Gondar, Ethiopia E-mail: asmphysio@gmail.com

Mob: +251-920-015-826 


\section{Abstract}

Background: Musculoskeletal disorders are growing public health problems both in developed and developing countries including Ethiopia. However, its prevention and control has not yet received due attention. This study aimed to determine.

the prevalence and associated factors of musculoskeletal disorders musculoskeletal disorders among cleaners of health institutions in Gondar town, Northwest Ethiopia

Method: An institutional based cross- sectional study was conducted, from April to May 2016 in all health institutions of Gondar town. All the available cleaners of health institutions were taken as study participants. Data were collected by face-toface interview technique after verbal informed consent. Additionally, weight and height of participants were measured following standard procedures. Data were collected by trained physiotherapists and then entered into a computer using Epi Info version 3.5.3 and exported to SPSS version 20 for analysis. Descriptive statistics was performed to describe the data in percentage and mean. Multiple logistic regressions were fitted and Odds ratios with 95\% confidence intervals were calculated to identify associated factors.

Results: A total of 242 participants were included in this study. The majority of the study participants were females (79.3\%) and between 25-44 age group (65.3\%). Two hundred One $(83.1 \%)$ of the respondents reported that they had pain in at least one of the body parts in the previous 12 months. Of the nine body parts examined, neck $(76 \%)$, upper back $(40.5 \%)$ and lower back $(45 \%)$ were the most frequently body parts reported to exhibit pain. Job status (AOR $=2.71,95 \% \mathrm{Cl} ; 1.37-5.36)$, and static work habit $(\mathrm{AOR}=2.71,95 \% \mathrm{Cl} ; 1.37-5.36)$, were factors associated with musculoskeletal disorders.

Conclusion: There is a high prevalence of musculoskeletal disorders among cleaners in the health institutions of Gondar Town. Job status and static work habit were the significant associated factors. Hence, we recommend the design and implementation of institution based screening programs for musculoskeletal disorders

Key words: cleaners, health institution, musculoskeletal disorders 


\section{Statement of the Problem}

Work-related musculoskeletal disorders are a major health issue in many occupations all over the world(1,2).Extensive research has been conducted on these musculoskeletal problems in different occupational groups such as health care professionals, building construction workers, office workers, bus drivers and sewing machine operators(3-6)

The cleaning services in health institutions represent one of the most dynamic occupations which expose cleaners to diverse occupational hazards including musculoskeletal disorders. A broad range of cleaning activities, from sweeping and vacuuming to disposing of waste or cleaning toilets is performed in health institutions. These Cleaning activities involve both dynamic and static muscular work with the use of various pieces of manual equipment. Cleaning work is generally labor intensive and involves repetitive movements, awkward positioning, and stretching which necessitate high cardio respiratory and musculoskeletal demands(7).

Factors contributing for the development of WMDs among cleaners in health institutions are wide spread and mostly occupational in origin(1,7-11). Sociodemographic factors (age and sex) and psychosocial factors are also important underlying factors for the progress of WMDS among cleaners in health institutions $(10,12,13)$

Ever since few studies have investigated work related musculoskeletal disorders among cleaners of health institutions both in developed and developing countries, there is limited information available for the prevalence and contributing factors of WMDs among cleaners of sub-Sahara African countries.. A knowledge gap therefore exists in scientific literature on the prevalence of WMDs and associated factors among cleaners of health institutions.).Therefore, this study aimed to assess the prevalence of WRMSDs and associated factors among cleaners of health institutions working at Gondar town. 


\section{2. Method}

\subsection{Study design and setting}

An institutional based cross-sectional study was undertaken in health institutions of Gondar town to assess the prevalence and associated factors of WRMSDs among cleaners of health institutions in Gondar town from April to May, 2016. It was conducted in health institutions of Gondar town. Gondar town is located 750kilometers from Addis Ababa, the Ethiopian capital. The town has 12 "kifleketemas" (sub-towns) and 21 kebeles(the smallest administrative units in Ethiopia) and is among the ancient and densely populated cities in Ethiopia having 206,987people according to 2007 Ethiopian Central Statistical Agency (CSA) office report $(14,15)$.

It has one referral hospital (UOG hospital), eight local governmental health centers and 42 private health institutions.

\subsection{Source and study population}

All cleaners working in health institutions of Gondar town were considered as source population. All cleaners who were available in all Hls of Gondar town during the data collection period were considered as study population. The total number of cleaners in the health institutions was 242 . The whole population was taken for the study due to being small population size.

\subsection{Inclusion and Exclusion criteria}

\subsubsection{Inclusion criteria}

All cleaners who were available in all Hls of Gondar town during data the collection

\subsubsection{Exclusion criteria}

All cleaners under 1 year work duration 


\subsection{Operational definitions}

Work related musculoskeletal disorders: perceived pain, ache or discomfort in any part of body segments caused, aggravated or exacerbated by work place exposures.

Body segments: neck, shoulder, upper back, lower back, hip/thigh, knee/leg and ankle/foot, wrist /hand

\subsection{Data collection tools and procedure}

A standardized structured questionnaire adapted from the Nordic musculoskeletal questionnaire, with modification to suit the local context consisting of both closed and open ended questions was used to collect the data. Data were collected using a combination of a structured questionnaire and measurements of weight and height. Data collectors were six physiotherapists supervised by investigators. Training and practical demonstrations on interview techniques and measurement procedures were given to data collectors for two consecutive days. The questionnaire was pretested on $5 \%$ of the study participants found outside of the study area and modifications were made on the basis of the findings. After completing the interview, the participant's height and weight were measured and recorded by interviewers. Weight measuring scales were checked and adjusted atzero level between each measurement and height was measured following the standard steps.

\subsection{Data management and analysis}

Data were coded and entered into Epi Info version 7 and exported to SPSS version 16 for analysis. Overall proportion with $95 \%$ confidence interval $(\mathrm{Cl})$ had been calculated to determine the prevalence. For testing of significance, categorical data were compared using chi-square test. Associated factors of WMDs were determined by using descriptive analysis. Multicollinearity test was also checked to assess the correlation between age and professional experience, height and BMI, sex and pregnancy. Logistic regression model had been used to assess the association of independent variables with WMDs. OR with 95\% (Cl) for risk indicators was calculated. The statistical tests were considered significant at a level $<5 \%(<0.05)$. 


\section{Ethical considerations}

The study was done after ethical clearance was secured from the Ethical Review Committee of College of Medicine and Health sciences, University of Gondar. Informed consent was obtained from study participants after being informed in detail about the objective, purpose, benefits and risks of the study. Appropriate measures were taken to assure confidentiality of information both during and after data collection. Identified subjects with WMDs during data collection time were given advice or referred, for further care, to physiotherapy

\section{Result}

A total of 242 cleaners (95.7\% response rate) from health institutions of Gondar town were included in this study. The majority of participants (79.3\%) were females. The mean age was $40.5 \pm 8.49$ years.

. The mean and standard deviation age of participants was 40.55 respectively. The majority of the participants were in the 25-44 age group, 158 (65.3\%).All the participants were from three types of health institutions, namely UOG referral Hospital (69.8\%), LGHIs (10.7\%), private HIs (19.4\%).The majority of the participants had working experience of less than two years. Table 1 shows the detail of the socio-demographic characteristics. 
Table 1: Distribution of cleaners by socio-demographic characteristics in Gondar town, 2016. $(\mathrm{n}=242)$

\begin{tabular}{lll}
\hline Variable & Frequency & $\%$ \\
\hline Sex & 192 & 79.3 \\
Female & 50 & 20.7 \\
Male & & \\
Age & 13 & 5.4 \\
$<25$ & 158 & 65.3 \\
$25-44$ & 71 & 29.3 \\
$>=45$ & & \\
Working experience(yrs.) & & 57.9 \\
$<2$ & 140 & 33.1 \\
$2-4$ & 80 & 9.1 \\
$>4$ & 22 & \\
Place of Work & & 69.8 \\
UOG Hospital & 169 & 10.7 \\
LGHls & 26 & 19.4 \\
Private HIs & 47 & \\
\hline
\end{tabular}

\subsection{Work -related and Psychosocial Characteristics of the Respondents}

The majority of the participants were in the group of 8 hours duration of work per day 156 (64.5\%). Participants with permanent job status were 223 (92.1\%). Majority of the respondents reported that they had no comfortable work schedule194 (80.2\%). Majority of the respondents reported that they had no time break 160 (66.1\%). Regarding job satisfaction $220(90.9 \%)$ reported that they were not satisfied with their job. Table 2 shows the detail of these factors. 
Table2. Work related and psychosocial characteristics of cleaners in Gondar town, $2016(n=242)$

\begin{tabular}{lll}
\hline Variable & Frequency & $\%$ \\
\hline Job status & & \\
Permanent & 223 & 92.1 \\
Temporary & 19 & 7.9
\end{tabular}

Comfortable work schedule

Yes

No

Time break

Yes

82

33.9

No

66.1

Job satisfaction

Yes

22

9.1

No

220

90.9

Job control

Yes

19

7.9

No

229

92.1

Duration of work/day (hrs.)

$<8$

50

20.7

8

156

64.5

$>8$

36

14.9

\subsection{Prevalence of musculoskeletal pain among cleaners}

Majority of the participants $201(83.1 \%)$ reported that they had pain at least in one of the body segments in the previous 12 months. The most prevalent body segments reported to exhibit pain among the participants were neck (76\%), lower back (45\%) and upper back 
(40.5\%), respectively. The following figure shows the prevalence of pain in the nine body parts.

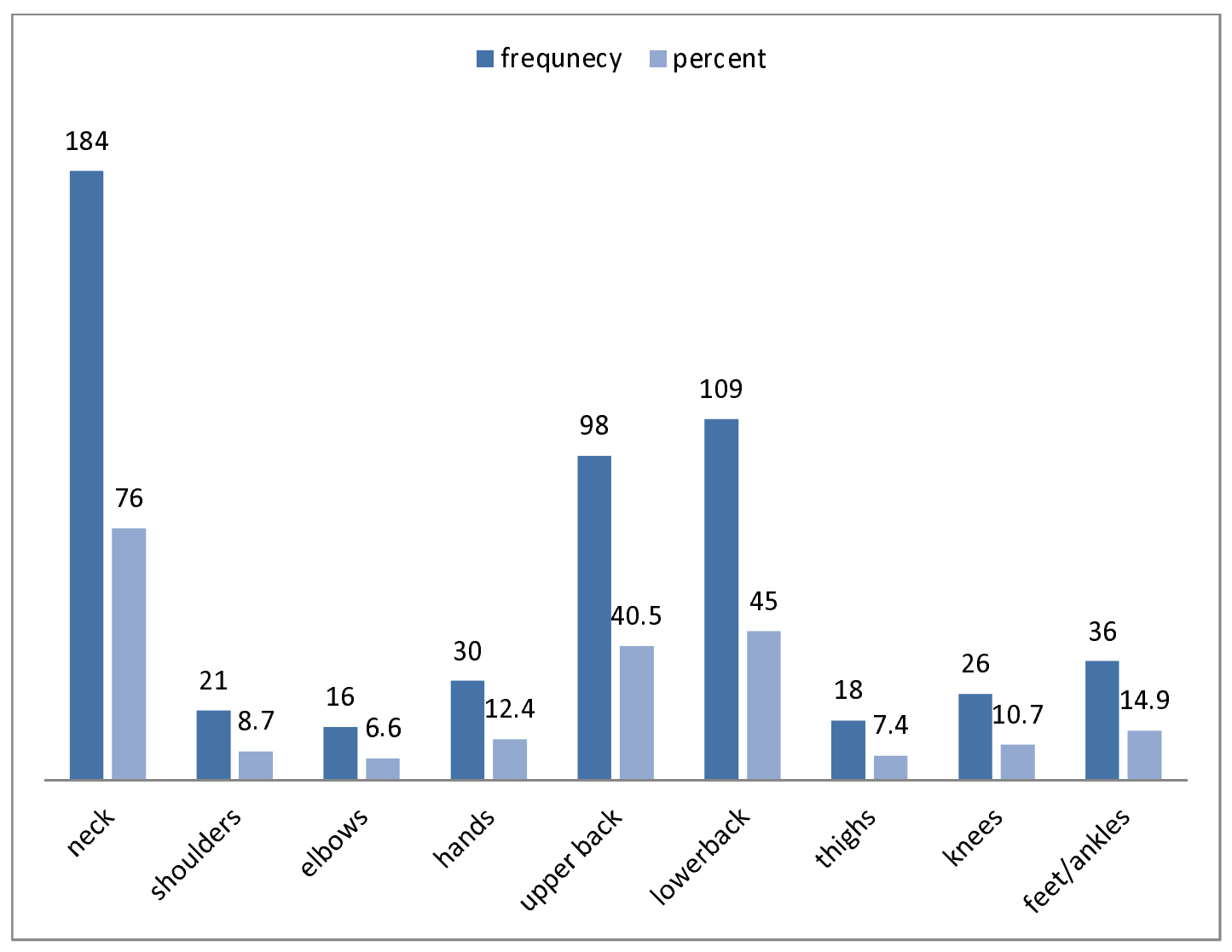

Figure 2: Prevalence of WRMSD on each body parts

\subsection{Factors associated with WRMSDs among the respondents}

Bivariate and multivariate logistic regression analyses were used to identify factors associated with WRMSDs among cleaners of HIs in Gondar town. The crude (COR) and adjusted odds ratios (AOR) together with their corresponding 95\% confidence interval were computed. Job status, static work habit, and comfortable work schedule were significantly associated variables with WRMSDs.

After fitting these associated variables in to multiple logistic regressions, job status and static work habit were independently associated with WRMSDs. 
Job status was found to be significantly associated WRMSDs. Those who had full time were $11.7(\mathrm{AOR}=11.17,95 \% \mathrm{Cl}(3.29,37.85))$ times more likely develop WRMSDs as compared to those of part time job status.

Static work habit was also found to be significantly associated to WRMSDs. The result showed those who had no static work habit were $70 \%$ times less likely to develop MSD than those with static work habit (AOR=0.271, 95\% $\mathrm{Cl} ;(0.107,0.689)$ ).

Table3. Results of binary and logistic regression for the associated factors of WRMSDs among cleaners in Gondar town, Northwest Ethiopia, $2016(n=242)$

\begin{tabular}{llll}
\hline Variables & $\begin{array}{l}\text { Musculoskeletal } \\
\text { Disorders }\end{array}$ & COR $(95 \% \mathrm{Cl})$ & AOR $(95 \% \mathrm{Cl})$ \\
& Yes $\quad$ No &
\end{tabular}

Job status

Permanent

Temporary

Static work

habit

Yes

No

33

168

16

25

$0.31(0.148,0.637)^{\star}$

1

$4.41(2.026,14.245)^{\star}$

1

$11 \cdot 17(3 \cdot 293,37.85)^{\star \star}$

1

Comfortable

work schedule

Yes

173

21

No

28

20

$5.84(2.833,12.223)^{\star}$

2.21(0.799, 6.097)

1

1

${ }^{*}$ : statistically significant at $\mathrm{p}<0.05,{ }^{* *}$ : statistically significant at $\mathrm{p} \leq 0.01, \mathrm{OR}$ : odd ratio, Cl: confidence interval, 1: reference 


\section{Discussion}

The purpose of this study were to determine the prevalence of musculoskeletal disorders musculoskeletal disorders and to identify the factors associated with musculoskeletal disorders among cleaners in health institutions of Gondar town in the previous 12 months. In this study, female workers made up the majority $(79.3 \%)$ of the cleaners. This was similar with the study done in Norway (82.8\%)(16)and Nigeria (92.4\%)(16).

This study found that about $83.1 \%$ of the participating cleaners complained of musculoskeletal disorders. This was close to the prevalence reported in Taiwan $90 \%(16)$. However, it was higher if compared with the reported prevalence of musculoskeletal disorders musculoskeletal disorders among cleaners in Norway56\%(16). The higher 12months prevalence found in the current study suggests that cleaners' practice in Ethiopia highly predisposes to musculoskeletal disorders. This may be a reflection of the work settings under which cleaners practice in Ethiopia.

The neck was the most affected body part with a percentage of $76 \%$ in this study. This was higher prevalence rate reported in comparison with the previous study as in Germany $(49 \%)(16)$. The difference may be due to work setting difference between developing and developed country. The causes of neck disorders may be due to performing repetitive movement lifting too much weight or lifting improperly.

The lower back was the second most affected body part with a percentage of $45 \%$ in this study. This was slightly higher prevalence rate reported in comparison with the previous study conducted in Taiwan (37.8\%)(16). The differences may be due to difference of work setting in developing and developed country in which the developed countries may use technologies that reduce stress for the back.

The upper back was the third most affected body part with a percentage of $40 \%$ in this study. This was higher prevalence rate reported in comparison with the previous study conducted in Norway $(21 \%)(16)$. The differences may be due to difference of work setting in developing and developed country in which the developed countries may use technologies that reduces stress to the back. 
Job status was significantly associated with WRMSDs. The permanent workers had higher prevalence of WRMSDs than the temporary workers (AOR=11.17, $95 \% \mathrm{Cl}(3.29,37.85)$ ). This may be due to the work load happened due to daily work. This finding was supported by a study conducted in Iran(16), in Taiwan(16) and China(16).

Static work habit was also significantly associated with WRMSDs (AOR=0.271, $95 \% \mathrm{Cl} ;(0.107,0.689))$. This may due to the fact that more stress is applied due to working in a fixed position so that they feel pain. This finding was supported by a study conducted in America(16).

\section{Limitations of the study}

The strength of this study is somewhat weakened because both exposure and musculoskeletal discomfort were ascertained by self-report, instead of objective documentation or medical records. Some of the included variables were not measured according to a standard measuring category.

\section{Conclusion}

This study interviewed 242 cleaners in health institutions of Gondar town to evaluate the prevalence and associated factors of WRMSDs. The prevalence of WRMSDs among cleaners of Hls in Gondar town was high. Among the nine body parts investigated, neck, upper back and low back were the most common body parts with musculoskeletal complaints. Job status and static work habit were identified as factors that affect WRMSDs. 


\section{Recommendation}

Based on the findings of the study, the following points are recommended to prevent and manage the magnitude of WRMSDs among cleaners of Hls in Gondar town.

\section{For researchers}

$\checkmark$ Further study with standardized measurement of important variables and data collection aided with medical records and other materials

$\checkmark$ Further study with wide geographical population

$\checkmark$ Further study with different study design such as RCT.

For clinicians- they are expected to giveadvice for cleaners related to work posture.

For employers- they are expected to consider timing of work and the way cleaners work in the organization

For policy makers- enforcing the establishment of preventive and curative aspects for WRMSDs 


\section{References}

1. Punnett L, Wegman DH. Work-related musculoskeletal disorders: the epidemiologic evidence and the debate. J ElectromyogrKinesiol. 2004;14(1):13-23.

2. Alamgir H, Cvitkovich $\mathrm{Y}, \mathrm{Yu} \mathrm{S}$, Yassi A. Work-related injury among direct care occupations in British Columbia, Canada. Occup Environ Med [Internet]. 2007 [cited 2017 Apr 6]; Available from:

http://oem.bmj.com/content/early/2007/05/23/oem.2006.031914.short

3. Yitayeh A, Mekonnen S, Fasika S, Gizachew M. Annual Prevalence of Self-Reported Work Related Musculoskeletal Disorders and Associated Factors among Nurses Working at Gondar Town Governmental Health Institutions, Northwest Ethiopia. Emerg Med Open Access [Internet]. 2015 [cited 2016 Dec 22];2015. Available from: http://www.omicsgroup.org/journals/annual_prevalence_of_selfreported_work_related_musculoskeletal_disorders-2165-7548.1000227.php?aid=36098

4. Kivi P, Mattila M. Analysis and improvement of work postures in the building industry: application of the computerised OWAS method. Appl Ergon. 1991;22(1):43-48.

5. Mattila M, Karwowski W, Vilkki M. Analysis of working postures in hammering tasks on building construction sites using the computerized OWAS method. Appl Ergon. 1993;24(6):405-412.

6. Walker-Bone K, Cooper C. Hard work never hurt anyone: or did it? A review of occupational associations with soft tissue musculoskeletal disorders of the neck and upper limb. Ann Rheum Dis. 2005;64(10):1391-1396.

7. Charles LE, Loomis D, Demissie Z. Occupational hazards experienced by cleaning workers and janitors: A review of the epidemiologic literature. Work Read Mass. 2009;34(1):105-16.

8. Hsieh Y-CJ, Apostolopoulos Y, Hatzudis K, Sönmez S. Occupational exposures and health outcomes among Latina hotel cleaners. Hisp Health Care Int. 2014;12(1):6-15. 
9. Tullar JM, Brewer S, Amick BC, Irvin E, Mahood Q, Pompeii LA, et al. Occupational safety and health interventions to reduce musculoskeletal symptoms in the health care sector. J OccupRehabil. 2010;20(2):199-219.

10. Krause N, Scherzer T, Rugulies R. Physical workload, work intensification, and prevalence of pain in low wage workers: results from a participatory research project with hotel room cleaners in Las Vegas. Am J Ind Med. 2005;48(5):326-337.

11. da Costa BR, Vieira ER. Risk factors for work-related musculoskeletal disorders: a systematic review of recent longitudinal studies. Am J Ind Med. 2010;53(3):285-323.

12. Bogale D, Tefera W, others. Assessment of occupational injuries among Addis Ababa city municipal solid waste collectors: a cross-sectional study. BMC Public Health. 2014;14(1):169.

13. Wahlström J. Ergonomics, musculoskeletal disorders and computer work. Occup Med. 2005;55(3):168-176.

14. 2007 Ethiopian Central Statistical Agency (CSA) office - Google Search [Internet]. [cited 2017 Apr 6]. Available from: https://www.google.com/webhp?ie=utf-8\&oe=utf$8 \&$ client=firefox-b\#q=2007+Ethiopian+Central+Statistical+Agency+(CSA)+office+

15. Ethiopia - Population and Housing Census of 2007 [Internet]. [cited 2017 Apr 6]. Available from: http://catalog.ihsn.org/index.php/catalog/3583

16. No Paul Buckley, www.hse.gov.uk/statistics $\square$ : Work-related Musculoskeletal Disorder (WRMSDs) Statistics, Great Britain, Health and Safety Executive (HSE), 2015.

1.Zock JP. World at work $\square$ : Cleaners World at work $\square$ : Cleaners. 2005;(December 2006).

2.Woolf AD, Pfleger B. Burden of major musculoskeletal conditions. 2010;81(03).

3. Paul Buckley, www.hse.gov.uk/statistics $\square$ : Work-related Musculoskeletal Disorder

4.Krause N, Scherzer T, Rugulies . Physical workload, work intensification, and prevalence of pain in low wage workers: results from a participatory research project with hotel room cleaners in Las Vegas. Am J Ind Med 2005;48:326-337. 
5.Sogaard K,Blangsted AK, Herod A, Finsen L. Work design and the labouring body examining the impacts of work organization on Danish cleaners' health. Antipode 2006;38:579-602.

6. Woods V, Buckle. Musculoskeletalill health amongst cleaners and recommendations for work organizational change. Int J Ind Ergon 2006;36:61 72.

7. HSE- Health and Service Executive, Upper limb disorders in the workkplace,2002.

8. WHO. Occupational health program of WHO Headquarters, Geneva, Switzerland. The Global Occupational Health Network 2003; pp.1-2.

9. Loewenson $\mathrm{RH}$. Health impact of occupational risks in informal sectors in Zimbabwe. In J Occup Environ Health 1998;4:264-274.

10.Jer Hao Chang, Jyun-De Wu, Chia-Yi Liu, and Der - Jen Hsu: Prevalence of Musculoskeletal Disorders and Ergonomic Assessments of Cleaners: American Journal of Industrial Medicine 55:593-604(2012)

11. Ilesanmi, Health Problems and Health Seeking Behaviour of HospitalCleaners in a Tertiary Health Facility in South West Nigeria, 2014.

12.Daniel Bogale, Abera kumie and Worku Tefera: Assessment of occupational injuries among Addis Ababa city municipal solid waste collectors: a cross-sectional study, 2014 ,14:169

13. Rev Esc Enferm USP: Quality of Life and musculoskeletal symptoms in hospital housekeeping workers: 2009, 43(2): 419- 425.

14. Jahn I, Ahrens W, Bruske-Hohlfeld I, Kreuzer M, Mohner M, Pohlabeln H.Occupational risk factors for lung cancer in women: results of a case-control studyinGermany. Am J Ind Med 1999;36:90-100. 1.Zock JP. World at work $\square$ : Cleaners World at work $\square$ : Cleaners. 2005;(December 2006).

15. Afamdi O.Ezenwa. A study of fatal injuries in Nigerian factories. Occup. Med2001;51:458489.

16.Smith DR, Wei N, Zhao L et al. Musculoskeletal com- plaints and psychosocial risk factors 
among Chinese hospi- tal nurses. Occup Med (Lond) 2004;54:579-582.

17.M Aghilinejad1*, AR Choobineh2, Z Sadeghi1, MK Nouri1, A Bahrami Ahmadi1Prevalence of Musculoskeletal Disorders among Iranian Steel Workers: Iran RedCrescent Med J 2012; 14(4):198-203 OIranian Red Crescent Medical Journal 18. Paul Buckley, www.hse.gov.uk/statistics $\square$ : Work-related Musculoskeletal Disorder (WRMSDs) Statistics, Great Britain, Health and Safety Executive (HSE), 2015

19. Palmer K, Smith G, Kellingray $S$ et al. Repeatability and validity of an upper limb and neck discomfort question- naire: the utility of the standardized Nordic questionnaire. Occup Med (Lond) 1999;49:171-175..

20. Bakker, A. B., Demerouti, E., \& Euwema, M. C. (2005). Job resources buffer the impact of job demands on burnout. Journal of Occupational Health Psychology, 10(2), 170-180. doi:10.1037/1076-8998.10.2.170

21.Brown JR. Factors contributing to the development of low back pain in industrial workers. Am industr Hyg ass J 1975 36:26-31 